\title{
Treatment barriers to social and health care services from the standpoint of female substance users in Finland
}

\section{Virokannas, Elina}

2020-07-03

Virokannas , E 2020 , ' Treatment barriers to social and health care services from the standpoint of female substance users in Finland ', Journal of Social Service Research, vol. 46 , no. 4 , pp. 484-495 . https://doi.org/10.1080/01488376.2019.1598532

http://hdl.handle.net/10138/322268

https://doi.org/10.1080/01488376.2019.1598532

unspecified

acceptedVersion

Downloaded from Helda, University of Helsinki institutional repository.

This is an electronic reprint of the original article.

This reprint may differ from the original in pagination and typographic detail.

Please cite the original version. 
Treatment barriers to social and health care services from the standpoint of female substance users in Finland ${ }^{1}$

\section{Abstract}

This study discusses treatment barriers affecting access to social and health care services from the standpoint of female substance users. The data consist of seven group discussions and three individual meetings with 13 women in Helsinki, Finland. Institutional ethnography by Dorothy Smith is used as the theoretical background. The focus is on exploring how people's lives are bound up in so-called "ruling relations" which organize their experiences.

The research questions consider women's personal experiences that are understood as being socially shared: What treatment barriers do women face; what reasons are there for them not receiving services, and how do the ruling relations coordinate women's experiences.

Women faced multiple barriers affecting their access to services. They could be interpreted as being: determined by the service system, such as a lack of services and difficulties in meeting the various criteria in order to be granted access to services; determined by the lack of trust, such as experiences of inequality and stigmatization, which created hopelessness; or determined by personal choices.

The study suggests that different sectors of the service system should break down the institutional barriers and co-operate closely in order to get an overall view of the complicated life situations of female drug users. Further, the service system should be organized according to the needs and wishes of the service users in terms of the availability and organization of services.

Keywords

Institutional ethnography, women, substance abuse, service system

\section{Introduction}

People who use illegal drugs encounter strong prejudices and resistance in the welfare service system regarding their involvement and receiving services. Drug users who have

\footnotetext{
${ }^{1}$ This study is part of a wider research project in which women who are in different vulnerable life situations and with different relations to the service system are studied (XXX). The study is being funded by Academy of Finland.
} 
severe health, financial, and housing problems might be turned away from service front desks or defined as unsuitable customers without explanation (Author; Paylor et al., 2012, pp. 47-48; Mulia 2012). In Finland, the number of those who suffer from severe substance addiction and remain totally out of the reach of service providers has been estimated as two or three times larger than the number of those who use those services (Partanen et al., 2014).

To some extent, men and women are treated differently in the service system, and there are different expectations of them (e.g. Taylor, 2010; Stone, 2015). Women, especially mothers, are not expected to use drugs in our society; they are under strict moral and societal control which might make seeking help difficult (Campbell N., 2000; Mulia, 2002; Author; Nelson, 2012; Hughes et al., 2015). As Lipsky (1980) has stated, drug abuse does not fit cultural stereotypes of ideal femininity which puts female dug users at risk of being categorized as 'unworthy' clients in the service system.

According to Tuchman (2010), there are significant gender differences in the epidemiology of substance use disorder, social factors and characteristics, health consequences, and factors related to treatment access, retention, and completion. However, gender-specific issues are often ignored when welfare services and substance abuse are studied. Traditionally, male participants have been overrepresented in substance abuse research and in other fields of public health research, and studies have been reported as gender-neutral. 
In this study, I focus on treatment barriers affecting access to social and health care services from the standpoint of female substance users. The data were obtained from group and individual discussions with women, gathered between August 2015 and August 2016 in Helsinki.

Institutional ethnography (IE) by Dorothy Smith is used as a theoretical background (e.g. Smith, 1987). According to Smith, institutions and professional discourses tend to exclude the standpoint of people living in the everyday world. Thus, the standpoint of people in vulnerable life situations is a necessary starting point for research work. By the concept of vulnerability, I do not mean that some people are somehow characteristically incapable or deficient. Rather, the problems they face are complex and the attitudes and labels placed on them by society combined with barriers to accessing services and support make their life situation vulnerable (see Fawcett, 2009; Brown, 2011).

\section{Literature review}

The treatment views of women have been the focus of previous research to some extent but such research has not been a mainstream topic. Hines (2013) studied the views of treatment by substance-abusing women by reviewing 30 qualitative studies published between 1992 and 2010. Treatment barriers typical to women included the fear of the treatment, domestic violence, stigma and shame, as well as cravings for drugs and 
alcohol. In addition, hopelessness was mentioned as a barrier to treatment. Similarly, in Taylor's (2010) review based on previous studies, fear of stigma was identified as an essential treatment barrier. In addition, lack of childcare and family support, lack of financial support and treatment availability, denial of addiction, and having cooccurring disorders such as mental disorders, were found.

In her own study, Mulia (2002) focused on low-income, drug-using women seeking care resources from institutions in the U.S. The network of institutional rules hindered women in accessing services. Conflicting sets of requirements between multiple service providers, women's relational tensions with treatment staff and negative attitudes caused them to leave without care or to withdraw from seeking services.

In Lavee's (2016) recent study of Jewish Israeli mothers living in poverty and their encounters with social service providers, the women seemed to be unware of what they were entitled to, or what domains welfare services were not responsible for. The women experienced assistance as being arbitrary. Feelings of humiliation, shame, and stigma were dominant and these affected not only women's perceptions of the system but also their perceptions of and feelings towards themselves.

In Finland, Leppo and Perälä (2009) have studied user involvement in two drug treatment institutions. These were a needle exchange and health counselling service, and a maternity clinic for pregnant women, which specialized in providing user- 
friendly services that provided "clients" with more choices than they had previously had. Yet, the researchers argued that the development of more listening and interacting services is challenging for professionals as they have difficulties in adopting new working methods and having more equal relationships with service users.

Based on previous literature, the problems women face when seeking services seem to be quite similar regardless of time and place. Lavee (2016) as well as Mulia (2002) almost twenty years earlier stress that in order to outline more effective ways to support low-income, substance-using women, research must focus on the experiences of those women (see also Rihter and Kobal, 2007). The current study continues this tradition by aiming to highlight the implications on practices by considering the standpoint of women living in complicated and thus vulnerable life situations.

\section{Local context}

The central feature of the Finnish drug treatment system was the partial liberalization of drug policy in the 1990s. The background of this improvement consisted of the increasing drug problems and the threat of an HIV epidemic (e.g. Tammi, 2007). The transformation was supposed to be a move towards user-friendly services where "customers" have more choice than they had previously. However, improvements have been criticized for remaining at the rhetorical level (Leppo \& Perälä, 2009). 
More recently, a huge reform project being led by the Ministry of Social affairs and health was started, concerning publicly funded health- and social services, and regional government (http://alueuudistus.fi/en/frontpage; https://www.thl.fi/en/web/socialwelfare-and-health-care-reform). The reform has been modified constantly since the beginning of the 2010 s, but it has not yet been applied to practice. I started my study and collected the data at the same time as the reform project has been subjected to regular debate in both public and political realms.

The major aims of the reform are to transform the responsibility for organizing services from municipal entities to autonomous counties, and the integration of services and freedom of choice, which are intended to improve primary health and social services in a cost-effective way. The reform project has been criticized for ignoring the complicated life situations of marginalized people and focusing on the position of service providers instead of service users (e.g. Hiilamo, 2015). According to critical views, there is a risk that the high-level service consumers' access to services get worse as local services decrease. Further, low income people with multiple needs are not the ideal service providers' target group.

\section{Theoretical framework}

Institutional ethnography offers a theoretical background that focuses on a critical analysis of the service system from the service user's point of view, which I found essential as new ways to organize services are being planned. However, individual 
experiences are not the main interest, but they are seen as being bound up in so-called "ruling relations" which organize their experiences (Smith, 1987, pp. 157-158; Grahame, 1998; Campbell M., 1998). By the concept of ruling relations, Smith (2004, pp. 79) means the "internally coordinated complex of administrative, managerial, professional and discursive organization that regulates, organizes, governs and otherwise controls our societies".

According to Smith (2004), power is generated and held especially in text-mediated relations. Legislation, directives and formal agency rules influence the beliefs, values and actions of social and health care professionals, encounters with clients and overall consequences for service users. For example, Brown (2006) used IE in her study of risk management strategies in Canadian child protection work. She showed how powerful professional and administrative discourses permeate the everyday lives of mothers as they tried to achieve desired outcomes in order to maintain the custody of their children. In Finland, Kuronen (2014) discussed how ruling relations might be analysed on the interactional, organizational, welfare state and societal levels by a study of the several texts that regulate cultural conceptions of ideal family life.

The research question of this study considers women's personal experiences, which I understand as being socially shared: What treatment barriers do women face and what reasons are there for them not receiving services and how do the ruling relations coordinate women's experiences? On the basis of the data analysis, I consider what 
should be taken into account when planning services further.

\section{Methods}

Data collection

The data were based on seven group discussions and three individual meetings with 13 women aged 25 to 55 . Group discussions were part of a wider health and social care project that aimed to reach the most marginalized female substance users and to help them receive the social and health care services they needed. The project's support group was open to all women who were able to stay awake and conscious during the sessions and did not behave aggressively. Commitment was not required, and women received counselling if they wanted it. The project was organized by the A-Clinic Foundation, and funding was received from Finland's Slot Machine Association (RAY).

Project meetings were held at a homely-furnished street-level place in an urban part of Helsinki. Project workers' offices were located in the same place but no other authorities worked there. The group discussions concerning the purpose of the research were usually held after the project's supporting group sessions and were also open to everyone. Thirty-two women participated in the larger project during the research period, thus $40 \%$ of them participated in the research. Participants did not receive any financial compensation for their participation, but coffee, snacks and fruit were offered during the meetings. Ethical approval for the data collection was granted by the ethics committee of the A-Clinic Foundation. 
Women's drug use was not asked about, but they talked about it quite openly. Participants had engaged in heavy drug use in some period of their life and most of them were still using drugs weekly or even daily. Some of them had multiple problems in several areas of their lives. They had a need for a range medical, financial, and social services. Some of the women were homeless. Only one woman was employed, and one was a university student, although she was not taking any courses during the research period.

From one to five women participated in each discussion: twice there were five, once four, once three, and on three occasions, there were two women in the group. Individual meetings were held three times: one time a woman wanted to participate alone and twice, only one woman showed up. One woman participated six times, another four times, and a third woman three times. Four women participated twice and six women only once. On seven occasions, a social work student whose master's thesis was based on the same data, was present (Liuski, 2016). The participating women could choose to remain anonymous, and their names or other identification information were changed as the audiotapes were transcribed. The transcribed data consisted of 350 single-spaced A4 sheets.

The women had been informed beforehand that the aim of the study was to consider 
their experiences with the social and health service system. ${ }^{2}$ According to my preunderstanding, women's situation in the welfare service system is complex and challenging. I had to be careful not to "invite" only bad experiences at our meetings. In order to give space to the women's experiences, I tried to keep the meetings as informal as possible and let the women lead the discussions and speak with each other (see Campbell M., 1998). If any participant asked for clarification of the purpose of our meetings, for example, someone who was participating for the first time, I repeated the description from the information letter. Otherwise I just listened and made short confirmative comments and occasionally asked more specific questions about something women had brought into the discussions. Thus, instead of using a certain interview protocol or structured questions, I understood the group discussions to be "conversations with a purpose" (Burgess, 1984, p. 102). The idea of this loose structure was to gain an understanding of the interviewees' ways of interpreting the issue and experiencing the social world (May 2011). Nevertheless, the discussion topics were mostly restricted to the experiences of service use.

I met some of the women several times during the year and gained a better insight into their life than if I had met them only once. However, about $60 \%$ of the women who

\footnotetext{
2 The information letter given to women was as follows: "My aim is to consider the social and health care system with the help of your experiences. It does not matter if you have not used these services for a while, you can still take part in XX-project. If you have needed services from doctors or social workers (for example) at some point in your life, but for some reason you had not sought support, you are just the right person to help me with my study. I would like to hear why you do not seek or receive support from the system. If you use some services (for example Vinkki [the Drop-In Needle Exchange program], health care centre, or social work office), I would like to hear why you use those services and what experiences of them you had. How have you been treated, what has gone well and what perhaps not so well?"
} 
participated in the project's support group did not want to participate in my research, and some of them disappeared as soon as I entered the room. Participant groups of qualitative studies are always selected in one way or another, and that should be noted as the results of the data analysis are being revealed. It could be that the basic distrust of anyone new, and the concept of the "outsider" were too prevalent for those women who did not even want to be seen. Also, some just did not believe that participating in research work would do any good. Still, those who participated made up quite a diverse group, and their experiences provided a good overall picture in regard to treatment barriers.

After finishing the data collection and writing up the first two manuscripts (Author, $2017 \mathrm{a} ; 2017 \mathrm{~b})$ I sent those to project workers to be given to the women. Then, in February 2017, I visited one support group meeting and presented my findings to the women. Only a few of the women had read the manuscripts beforehand but a few joined the discussion after my presentation. No one wanted to change anything, and I the feedback I got indicated that I had correctly understood our discussions.

Data analysis

I relied on institutional ethnography when planning the research setting and conceptualizing the phenomenon to be studied. It meant that my purpose was not to generalize about the group of people on the basis of my data, but to analyse social processes that have generalizing effects (see DeVault \& McCoy, 2006). Further, I 
understand group discussions to be social products (Gubrium \& Holstein, 2009). They have the capacity to express women's "actual" standpoint, and at the same time, they should be interpreted as narratives produced in a certain context (Miller \& Glassner, 2004, p. 135).

To analyse the data, I first selected all episodes concerning talk about treatment barriers and the difficulties in obtaining services. This kind of talk was found at every group discussions and at all individual meetings as it was one of the main topics discussed. Next, I continued by specifying categories concerning different treatment barriers. That is, what variations were there between the reasons for not getting or seeking support, how were they defined by the women, and from what positions were they discussed (see Wood \& Kroger, 2000). Furthermore, I discovered that all the barriers and difficulties reflected more or less the relations between women and the service system in general or in interactions with certain staff members or authorities. Finally, I considered how the ruling relations seemed to coordinate women's experiences and their orientation to services and help seeking.

I did not separate the barriers faced by the women concerning healthcare and social services, for example; that is the more traditional and system-centred way to look at them. Instead, the categorization of treatment barriers in the analysis was based on how things look from the women's standpoint. 


\section{Analysis: Treatment barrier categories in discussions with women}

According to my data, women face several barriers to treatment when seeking support. The women repeatedly discussed their feelings about the way the service system works, how it was difficult, how things did not proceed, how their needs remained unmet, or how their access to services was totally prevented. In some cases, they chose not to use the services available for other reasons (see also Hines, 2013).

At one extreme, the treatment barriers women identified could be interpreted as being determined by the service system: such as a lack of services or information and difficulties in fulfilling criteria in order to be granted access to services. In the middle, some of the barriers were defined as determined by the lack of trust. These included experiences of inequality and stigmatization, which created hopelessness, helplessness, and finally giving up seeking support. Thus, emotions and subjective ways of reacting played an important part in this category.

At the other extremity, not all the reasons which came up in discussions were defined as arising from the service system or distrust, but were instead described more like personal choices. Those concerned the individual life situation of the women, and even if they were connected to the service system, they were expressed by emphasizing the women's own will and choice, like being unwilling to stop using substances in their current life situation. 
Barriers determined by the service system

Scarcity of or long waiting lists for services were the clearest barriers that were defined as being entirely determined by the service system in the discussions. Some women explained that they had spent more than a decade on a waiting list for city housing, which made their situation desperate. One of them sadly died soon after the group discussions ended. Close to scarcity and long waiting times were a lack of information and confusion about what services they were entitled to. The women also discussed getting one's needs met only with the help of other service users, rather than by using formal services. Similarly, according to Lavee (2016), service users might have received information about their eligibility for social services through their social networks, not through welfare service agents. Women also said that access to services might depend on a single social worker, and if one lacked the right kind of relationships, it was harder to get in. Thus, one barrier was a lack of connections.

The denial of proper health care services came up in a few discussions. Cecilia, for example, lost the fingers from one of her hands because she had injected incorrectly into an artery and did not get first-aid. Treatment was delayed as she had been turned away from the emergency clinic of a hospital. The first extract is from a conversation between one women with a project worker and the researcher. 
Cecilia $^{3} \quad$...it took so long, and finally we [she and her boyfriend] just / I cannot, I can't stand anymore. They didn't do anything. They just let us sit there // in the corridor.

Researcher [They did not look at your hand or anything?

Cecilia [No, no nothing. They didn't look at my hand or anything. We just were yeah, painkillers. I screamed help and / for pain and everything. They just yeah, painkillers, and then they let us sit on the / fucking corridor bench. / And I went several times to ask what are you going to do, what are you doing, what is going to happened, could you help me? / No nothing, nothing was given. /// No nothing, no prescription. / No help. They didn't talk anything. They just looked at me like I was one junkie there...

Cecilia described how she desperately tried to get help from the first aid clinic after her painful accident but was treated like a junkie with no human dignity. Later on, her story came out; she was told that her injury was her own fault and that she should just take painkillers and go home. A few weeks later when she finally got into treatment and her hand was operated on, it was too late to save her fingers. Cecilia's position seems to be one of a mistreated, helpless victim who is entirely ruled out by first aid staff members.

\footnotetext{
${ }^{3}$ All names are pseudonyms. Slashes refer to breaks in the speech, a short break is shown as one slash, /, and two slashes, //, mean a longer break of over one second. Empty parentheses, ( ), refer to unclear speech. Square brackets, [ ], between speakers show overlapping speech between speakers, while within the text they show implied concepts that might be necessary in order to follow the direction of the speech. The discussions were conducted in Finnish. The extracts have been translated into English in a manner allowing for the original form to be preserved as much as possible.
} 
Another barrier to services that is also determined by the service system came about due to structural changes to street level services, which are essential for intravenous drug users. The process was ongoing during the year I collected the data. The Drop-In Needle Exchange program (Vinkki), organized by the A-Clinic Foundation, stopped getting funding due to the system of competitive tendering for health and social services. Instead, a new service provider received the funding and started new Drop-Ins at new locations. Vinkki had served drug users for 15 years and had managed to gain their confidence. A new service provider with new employees had to start everything from scratch. The issue was discussed at several meetings. The following extract is from a conversation between two women, a student and the researcher.

Kaisa Everything changed again. I mean, / let's build again everything, maybe something new. And it is always, you know, / people are thrown from one place to another. I mean, just when you have started to trust something // in someone // it ends / and then, you must again, you know. // [(-)

Reetta [Yeah and you wait all the time that when it / when you are thrown again.

Kaisa and Reetta described the ongoing change in street level services as something arbitrary that comes from somewhere that is out of their own control and ignores their efforts to seek support. As such, this process is a perfect example of what Smith (2004) means by ruling relations that are created in administrative level texts and when put into 
practice, organizes and governs the lives of powerless people. Furthermore, the women defined this state of unpredictable affairs as permanent. Thus, it prevents their willingness to trust and attach support to new service providers.

The same topic continued in another group meeting with other participants, this time involving five women, a student, and the researcher. Maija, who is an experienced peer worker for other drug users, described how she went to look for a new Drop-In with a group of reporters.

Maija I knew it was located somewhere on the other side of / Malmi [district], and / we left / to dawdle there and I had no clue hhh [laughs]. / And we asked people. No one knew where it was. We found it in some backyard, / sort of a cellar door which looked like the door of a bicycle cellar. / Though there was a camera outside, directly, about which people have afterwards complained hhh [laughs]. But you know, there was nothing else there but / Drop-In Needle Exchange, / former-Vinkki, / welcome / and phone number. No information / when they are open / [--] It had been open for four weeks and people didn't know, users from the neighbourhood who live there in Malmi. / If even they don't know where the place is, it does not sound good. 
Maija emphasized how providing information about the locations and opening times of the new Drop-Ins had failed, and people who needed the services did not get them. Furthermore, being able to visit Drop-Ins anonymously was violated by the location of a surveillance camera above the entrance. The whole episode was described with laughter, which could be interpreted as an expression of confusion concerning the reform process. However, all three women, Kaisa, Reetta, and Maija, consider these structural changes as members of the larger drug using group's position - not just from their individual perspective, as Cecilia had done in her case. They seemed to be conscious of the administrative and managerial level ruling relations that govern their ability to obtain services even if they did not use that kind of terminology.

Finally, rigid bureaucracy and failure to fulfil the criteria applied by the service system were common reasons that created treatment barriers and caused frustration (see Mulia 2002). In other words, the current life situations of women were not always suited to the services available. For example, one previously homeless woman had not taken up a residence she was offered because it was so small that her children who had been placed in foster care could not have visited her.

Kaisa has a long history with substances. She had been using illegal drugs for 30 years and had sought treatment several times. She eventually went through a few therapy periods that ended up in disappointment. Most often, Kaisa was unable to gain access to 
treatment due to her failing the required drug tests. There were two women, a student and the researcher present in the next conversation.

Kaisa Everything always ended up about that test thing... [--] I mean / I was in despair because I did not pass the tests and // I mean I could not, in a way, get a chance to [start anything.

Researcher $[\mathrm{Mmh}$, yeah.

Student $\quad[$ Yeah.

Kaisa I mean, / it takes at least / a couple, / well at best it takes three months.

Researcher To pass the tests.

Kaisa Totally.

Kaisa does not blame the service system for her difficulties in passing the drug tests, but neither does she entirely take responsibility herself. She defines herself as incapable of passing the tests, but the main reason for her incapability is the qualities of the drug, in this case cannabis, which stay in the person's system for a long time. However, her lack of opportunity to start new treatment seems implicitly to originate from the rigid regulations of the service system. In common with all treatment barriers presented so far is that the women themselves do not seem to be able to overcome those obstacles. The barriers are determined by the governing institutional ruling relations as well as the practices of the structural organization and distribution of services. 
Barriers determined by the lack of trust

In the next category are the reasons for not receiving services derived from the feelings, beliefs, and conclusions women made based on their experiences of the service system. A lack of trust and suspicion resulting from their previous experiences created barriers for seeking help. Not surprisingly, the child welfare services were considered to be the biggest culprit as there could be very different expectations between social workers and drug using women and a fear of losing one's children (see also Nelson, 2012, p. 24; Taylor, 2010). Stone (2015), in her study of women who were pregnant and on methadone, addressed how women did not get information about what would happen after their babies were born. They were confused by the lack of information and felt betrayed by treatment professionals. Stone suggests that communication between medical staff and mothers is essential in order to ease confusion and reduce feelings of stigmatization and unfair treatment.

In the following extract, Reetta has just told the other three women taking part about her divorced friend who became tired of being a single parent and sought support from the child welfare services. The child was placed in temporary foster care, and Reetta fears that her friend will never get her child back. Ilona, another woman, continued the discussion with her experiences of child welfare services.

Ilona This is so awful because you cannot seek support from child welfare services. 
Jaana $\quad[$ Yeah.

Ilona [I went there to seek support.

Researcher [Yeah.

Ilona I mean // mmh /// really, you do not dare to go there, you know, to tell anything, that I am tired or anything because you will end up in some sort of investigation. I mean, your children end up being observed by a psychiatrist.

[A few lines about Ilona's situation have been removed, and Reetta continues with the situation of her single parent friend.]

Reetta $\quad$...You would rather take your kid for a day to there [to grandmother's place], go to your home for a rest, // take care of yourself. // I mean, like that. And then pick up your kid or spend the night there too. Rather, / than drag a social worker in. I mean, give your kid to social workers.

Ilona Yeah, it is certainly the last thing to do I mean really. You know, or mention anything about any drugs.

The barrier to getting support here differs from previous examples, as the services would be available if women sought them. Ilona had sought services, and as a result, her family had ended up under surveillance. She lost her children to her ex-husband, something which came out during another part of the discussion. On the other hand, Reetta would recommend any other way to solve one's problems than going to social 
workers to ask for help. All three women in the extract had children, and none of them had custody. Furthermore, no one expressed positive experiences with child welfare services. Thus, the suspicion that support would be available even if access to services was available was shared and confirmed with other women.

Shame, and lack of faith were barriers which were combined with both the poor quality and scarcity of services. The poor quality of help or the humiliating way help had to be sought caused shame, and in order to maintain self-esteem it was better to refuse and leave without help than submit oneself to poor services. For example, unisex rooming houses for homeless people were described as being noisy, disorganized, and full of drugs and alcohol that it was impossible for women to live there sober, feel safe and get one's life situation organized.

The food bank queues were experienced as especially difficult and humiliating ways to seek help (see also McIntyre et al., 2003). The queues could be extremely long, and the quality of food varied. Some women said that it was better to stand in line than starve, and standing in line was the last option. The need to seek help from the food bank was felt as being unjust. Maija recalled her experiences in the food bank queue in a discussion between five women, a student and the researcher.

Maija I was there [food bank queue] over an hour but I got so distressed and, / I mean, I was so embarrassed. And then I thought all these cars, and 
everyone will see me standing in line and, / you know, that I simply did not have the nerve to stand there. / I got the feeling that, / in my opinion, I am not supposed to stand there.

[A few lines removed.]

Maija $\quad .$. shouldn't this be some fucking welfare state, so why the fuck do people stand there in line!

Maija described the shameful feelings she had when standing in the food bank queue. Afterwards, she decided it is better to refuse such humiliating support, and furthermore, that it is not right that she should seek help like that. Maija expressed with strong emotion her opinion of the welfare state's failure to help people with dignity. As such, she once more expressed her criticism and awareness of ruling relations that force some people to be dependent on humiliating help.

In Jaana's extract, she no longer has faith in services after several disappointments. Jaana has had problems with her back for many years, but it had not been looked at properly. Jaana thought that the reason was her status as a drug user. There are four women, a student and the researcher in the conversation.

Researcher Do you have continuous pain, I mean everyday pain in your back?

Jaana Well yes. It varies a bit how painful it is, but now the pain has been present for several days. And I don’t know, I don’t feel like making an 
appointment to see the doctor just because I know, you know, what they will say. I have been there so many times and, / well, / I mean. // I don't know. I would like to get it X-rayed because you know, it is in my spine. I mean, there must be something wrong there.

[A few lines removed.]

Student But you said that / you don't even feel like making appointment so, I mean. /

Jaana $\quad[$ Yeah.

Student [Do you mean that, / if you would have some other need / to see the doctor, so what would you [/ think about that?

Researcher [Yeah, would you not use other service neither because you do not expect $[$ much...

Jaana [Well, / yes. I would not, I mean, because. // It is like, / at once they see my files you know, they, / [well / their behavior always changes.

Jaana would have a good reason to seek treatment for a doctor. The reason for not doing so is not the scarcity of services or long queues, but the lack of faith that she will receive proper treatment. The institutional practice, which is governed by administrative guides, produces files for individuals with the "drug user" stigma. From the women's standpoint, the stigma justifies different treatment for stigmatized service users like women who use drugs. In Jaana's case, because she had experienced being stigmatized as a junkie in some services, she was prejudiced about all services. As a result, 
malpractice coordinated by institutional ruling relations creates a treatment barrier as the woman loses her faith in the service system.

Barriers determined by personal choices

Treatment barriers described earlier were defined as being determined mostly from the way the service system works and thus, those were out of women's control. Or, if experiences of services were described as being emotionally challenging, women seemed not to have resources to overcome those. Here though I present a treatment barrier that is defined as being derived mainly from the personal choices of women. Barriers of this type emerged in only a few discussions.

Niina had suffered from mental health problems since she was a teenager. She had also occasionally used psychoactive drugs for recreational purposes and for self-meditation. She used to get therapy for her mental health problems until her drug use was revealed and the therapy ended against her wishes. The first extract is from the conversation between three women and the researcher, and the second one is from a conservation between Niina and the researcher two months later.

Researcher Did you leave totally / out of / all services / when you ended [therapy sessions]?

Niina Mmm well, I did, / I did go to XX's emergency once when I was so depressed that I thought that maybe I should get in [to inpatient mental 
treatment] again or. / But there I bumped into that, you know, I should first go to // talking to the eastern / drug clinic. / First. And they would evaluate me there. And not until then could I get back into therapy. / So, I did, / I went during this spring / there, / to the drug clinic to talk. // But / then I decided that / I am not ready to stop this, my drug use, I mean. I still want to go to those / parties and do trips inside my head. / And if this system does not, // if there is a zero tolerance in this system, well in that case I find visits to the drug clinic as being useless.

Niina ... And then because of my records I should give / those tests and somehow, there is this, my values, I mean the kind of / they finger me / information is taken from my body / I mean / it // it somehow...

Niina chooses not to give up psychedelic drugs even when she has been depressed and would need therapy. In order to start therapy again, it was demanded of her that she produce clean drug tests. Furthermore, she did not agree to expose her body for the tests. Even if the demand for negative tests comes from the service providers Niina does not blame the system for denying treatment. She just states that the system has a zero tolerance of drugs, and in that case, she does not fit into the system. No one else makes the decisions for her. At some point, she conformed to the demands that she should go to the drug clinic to be evaluated, but finally she came to the conclusion that she would rather leave without therapy than give up drugs. 
Unlike Kaisa, who also struggled with drug tests but defined herself as being incapable of passing them, Niina's position is more like that of an independent actor who calculates her options and makes her choice. However, her independence is limited as the system does not give her any choice other than "take it or leave it". That is why I interpret also this category as an implication of administrative ruling relations, which regulates choices made at the individual level.

\section{Conclusion}

Similar to previous studies (e.g. Hines, 2013; Taylor, 2010; Mulia 2002), according to my analysis, female drug users faced multiple barriers affecting their access to social and health care services. Treatment barriers were formed when there was insufficient information about the services available or no services at all. Other barriers were determined by the system in situations in which services were offered but women felt that those were not right for their current situation. On the other hand, their life situation was defined as somehow lacking the criteria necessary to fulfil the requirements of the service system and thus was felt to be troublesome. In order to have a sense of control over a dehumanizing social environment, it felt better to refuse the services if their quality was considered to be so poor. 
In the category of barriers originating from the lack of trust, the most commonly shared experiences were frustration, feelings of being stigmatized, not worth care and treatment, and a lack of faith and shame. Even if those seemed like individual emotions, they were widely shared between the women and arose due to administrative and institutional practices. When denial of treatment was defined as being a result of selfchoice, the context of limited boundaries set by the system is not clearly recognized anymore.

As a result of a range of barriers, women did not receive services, and their needs remained unmet. Their everyday life seems to be experienced as disorganized and lacking sense as they are dependent on public services that look unpredictable and arbitrary from their standpoint. Further, their perceptions towards themselves as humiliated and unworthy persons are bound up with the rules and practices of the service system. Their choices to seek services or to have them withdrawn are coordinated by the ruling relations that regulate their face-to-face interaction with professionals as well as organization of services and ideologies and values of welfare state.

However, the women expressed many critical views about the system and "talked back" (Juhila, 2004) to stigmas attached to them by the service system. That kind of talking back could be interpreted as denial of one's own responsibility and addiction. On the other hand, it could be seen as an effort to keep one's self-respect. According to my 
data, if the criticism of the service system was represented from "our drug using women's" standpoint instead of presenting it as individually encountered inequality, there would be more efforts to not give up support seeking.

The freedom of choice, intended by the Finnish reform project, might seem to be quite unrealistic because it requires knowledge and social and economic resources that people who are high-level service consumers often do not have. Furthermore, there is the risk that the freedom intended for service users instead increases the freedom of service providers to reject unwanted clients. For example, in Norway, the Substance Treatment Reform that started in 2004 with similar goals, had unexpected influences as "patients' rights" became an instrument for reducing the obligations of the health enterprises (Nesvaag \& Lie, 2010). In addition, the idea of service users as calculating consumers, which is implicitly present in the ongoing reform project in Finland, does not fit with the vulnerable life situations of drug-using women or any other service user group that struggles to survive instead of shopping comfortably for services.

Many of the barriers and risks of the intended reforms discussed here apply to male substance users as well. However, female drug users have traditionally been in the minority among service users, they have been subjected to violence by men and cultural expectations for women are more penetrating than for men (e.g. Taylor, 2010; Tuchman, 2010). Based on the fact that my findings are compatible with previous studies (e.g. Hines, 2014), women prefer gender-specific services, and high-quality 
services, which should be offered in a safe environment with easy access. They would benefit from an approach which conveys to them that they are not alone, that they are respected, and that their needs will be taken seriously. The chance to create safe and encouraging relationships requires time and certainty for continuity. Thus, for example, frequent competitive tendering does not benefit female - or male - service users.

The task for research work in the tradition of IE is to point out that the reasons for seeing one's life as pointless does not lie in individual or local situations, but rather at the institutional and administrative levels (Smith, 1987; Grahame, 1998). Social and health care services should co-operate closely to get an overall view of complicated life situations. The different sectors of the service system should break down the institutional barriers and should stop labelling individuals as unsuitable for services. That task is too much for single staff members or single projects but should be the starting point for organizing and producing services. Further, the service system should be organized according to the needs and wishes of the service users in terms of availability and organization of services.

\section{References}

Brown, D. J. (2006). Working the System: Re-Thinking the Institutionally Organized Role of Mothers and the Reduction of "Risk" in Child Protection Work. Social Problems, 53(3), 352-370. 
Brown, K. (2011). "Vulnerability": Handle with Care. Ethics and Social Welfare, 5(3), $313-321$

Burgess, R. G. (1984). Autobiographical accounts and research experience. In R. G. Burgess (Ed.), The Research Process in Educational Settings: Ten Case Studies (pp. 251-270). Lewes: The Falmer Press.

Campbell, M. L. (1998). Institutional Ethnography and Experience as Data. Qualitative Sociology, 21(1), 55-73.

Campbell, N. D. (2000). Using Women. Gender, Drug Policy, and Social Justice. New York: Routledge.

DeVault, M. L., \& McCoy, L. (2006). Institutional Ethnography: Using Interviews to Investigate Ruling Relations. In D. E. Smith Ed.), Institutional Ethnography as Practice (pp. 15-44). London: Rowman \& Littlefield Publishers, INC.

Fawcett, B. (2009). Vulnerability. Questioning the certainties in social work and health. International Social Work, 52(4), 473-484.

Grahame, P.R. (1998). Ethnography, Institutions, and the Problematic of the Everyday World. Human Studies, 21(4), 347-360. 
Gubrium, J. F., \& Holstein, J.A. (2009). Analyzing Narrative Reality. London: Sage.

Hiilamo, H. (2015). Hyvinvoinnin vakuutusyhtiö - Mistä sote-uudistuksessa on kysymys? Helsinki: Into.

Hines, L. (2013). The treatment views and recommendations of substance abusing women: A meta-synthesis. Qualitative Social Work, 12(4), 473-489.

Hughes, J., Chau, S., \& Vokrri, L. (2015). Mothers' Narratives of their Involvement With Child Welfare Services. Affilia: Journal of Women and Social Work, 31(3), $344-358$.

Juhila, K. (2004). Talking Back to Stigmatized Identities: Negotitation of Culturally Dominant Categorizations in Interviews With Sheltered Resident. Qualitative Social Work, 3(3), 259-275.

Kuronen, M. (2014). Perheen ideologinen tuottaminen. In R. Jallinoja \& H. Hurme \& K. Jokinen (eds.) Perhetutkimuksen suuntauksia. Tallinna: Gaudeamus, 81-98.

Lavee, E. (2016). Low-Income Women's Encounters with Social Services: Negotiation over Power, Knowledge and Respectability. British Journal of Social Work.

DOI: https://doi.org/10.1093/bjsw/bcw131 
Leppo, A., \& Perälä, R. (2009). User involvement in Finland: the hybrid of control and emancipation. Journal of Health Organization and Management, 23(3), 359-371.

Lipsky, M. (1980). Street-level Bureaucracy. New York: Russel Sage Foundation.

Liuski, S. (2016). Poikkeavuuden kategorioita huumeita käyttävien naisten ryhmäkeskusteluissa. Pro Gradu -tutkielma, Jyväskylän yliopisto.

May, T. (2011). Qualitative Interviewing: Asking, Listening and Interpreting In T. May (Ed.) Qualitative Research in Action (226-241). London: Sage.

McIntyre, L., Officer, S., \& Robinson, L. (2003). Feeling poor: The felt Experience of low-income lone mothers. Affilia: Journal of Women and Social Work, 18(3), 316-31.

Miller, J., \& Glassner, B. (2004). The "inside" and "outside". Finding realities in interviews. In D. Silverman (Ed.) Qualitative Research. Theory, Method and Practice (2nd ed., pp. 125-139). London: Sage.

Mulia, N. (2002). Ironies in the pursuit of well-being: the perspectives of low-income, substance-using women on service institutions. Contemporary Drug Problems 29(4), $711-748$. 
Nelson, A. (2012). Social Work with Substance Users. London: Sage.

Nesvaag, S. \& Lie, T. (2010). The Norwegian substance treatment reform. Between New Public Management and conditions for good practice. Nordic Studies on Alcohol and Drugs 27(6), 655-666.

Partanen, A., Kuussaari, K., Forsell, M., \& Varis, T. (2014). Päihdepalvelut. In Kunnallistalouden ja -hallinnon neuvottelukunta. Peruspalvelujen tila -raportti 2014. II osa - liiteosa. Valtiovarainministeriön julkaisuja 9/2014, II osa, pp. 189-207.

Paylor, I., Measham, F., \& Asher, H. (2012). Social Work and Drug Use. Berkshire: McGraw-Hill, Open University Press.

Rihter, L., \& Kobal, B. (2007). "I look like a mess... Am I needed in the profit oriented society?" The labour market and employment situation of some vulnerable categories of unemployed and inactive people in Slovenia. Revija Za Socijalnu Politiku Journal of Social Policy, 14(3-4), 373-390.

Smith, D.E. (1987). The Everyday World as Problematic. A Feminist Sociology. Oxford: Open University Press/Milton Keynes. 
Smith, D.E. (1990). Texts, Facts, and Femininity: Exploring the Relations of Ruling. London: Routledge.

Smith, D.E. (2004). Writing the Social. Critique, theory, and investigations. Toronto: University Toronto Press.

Stone, R. (2015). Pregnant women and substance use: fear, stigma, and barriers to care. Health \& Justice, 3(1), 1-15.

Tammi, T. (2007). Medicalising Prohibition: Harm Reduction in Finnish and International Drug Policy. Helsinki: Stakes Research Reports 151.

Taylor, O.D. (2010). Barriers to treatment for women with substance use disorders. Journal of Human Behavior in the Social Environment, 20(3), 393-409.

Tuchman, E. (2010). Women and Addiction: The Importance of Gender Issues in Substance abuse Research. Journal of Addictive Diseases, 29(2), 127-138.

Wood, L.A., \& Kroger, R.O. (2000). Doing Discourse Analysis: Methods for Studying Action in Talk and Text. London: Sage.

Web pages 
http://alueuudistus.fi/en/frontpage

https://www.thl.fi/en/web/social-welfare-and-health-care-reform 